\title{
NVLAP Assessor Selection and Training
}

Harvey W. Berger

U.S. DEPARTMENT OF COMMERCE National Bureau of Standards

Associate Director of Industry and Standards

Gaithersburg, MD 20899 

NBSIR $87-3651$

NVLAP ASSESSOR SELECTION AND

TRAINING

Harvey W. Berger

U.S. DEPARTMENT OF COMMERCE

National Bureau of Standards

Associate Director of Industry

and Standards

Gaithersburg, MD 20899

September 1987

U.S. DEPARTMENT OF COMMERCE, Clarence J. Brown, Acting Secretary NATIONAL BUREAU OF STANDARDS, Ernest Ambler, Director 


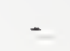




\title{
ATIONAL VOLUNTARY LABORATORY ACCREDITATION PROGRAM (NVLAP)
}

\author{
SSESSOR SELECTION AND TRAINING
}

larvey W. Berger, Manager

lational Voluntary Laboratory Accreditation Program (NVLAP)

\section{:NTRODUCTION}

The National Voluntary Laboratory Accreditation Program (NVLAP) is Idministered by the National Bureau of Standards (NBS) for the purpose of ecognizing competent testing laboratories. As an agency of the US Department if Commerce, NBS is concerned with international acceptance of test data, increased trade, and elimination of technical barriers to trade. NVLAP iddresses these objectives and also contributes to improved quality of testing ind improved test methods.

The opportunity for accreditation is offered for specific test methods or :ypes of tests in specified fields of testing to all domestic and foreign laboratories. NVLAP does not offer "blanket accreditation" by field of esting. Test methods developed by US and foreign standards organizations or zovernment agencies can be offered for accreditation by NVLAP. Private company test methods can also be offered for accreditation if those methods are accessible to all applicant laboratories. A condition for inclusion of sny test method in a NVLAP program is that it be of sufficient technical quality to permit the differentiation between laboratories that can or cannot perform it in a competent manner.

\section{DEMONSTRATION OF LABORATORY COMPETENCE}

Laboratories demonstrate their competence through compliance with NVLAP accreditation criteria, which address the laboratory's quality systems, staff, facilities, equipment, calibration schedules, implementation of test methods, documentation, operational procedures, records management, and test reporting. The general criteria for accreditation are published as part of the NVLAP Procedures in the US Code of Federal Regulations. Criteria which address test methods in a particular testing technology (or field of testing) are published in NVLAP Technical Handbooks.

The determination of a laboratory's competence is based on two, fundamental, NVLAP-directed activities: proficiency testing and on-site assessments by technical experts.

\section{PROFICIENCY TESTING}

Successful proficiency testing is a condition of continuing accreditation in all programs. The requirements of the programs differ, depending on opportunities, costs, difficulty in performing specific tests, availability of test artifacts, cooperation of other organizations (such as standards committees), and other external factors. Proficiency testing is required for selected test methods if such testing is deemed necessary to determine or reaffirm laboratory competence to perform that method. Laboratories seeking accreditation for those selected methods must participate in the associated 
proficiency testing programs. The results of an individual laboratory's proficiency testing provide an indication of the laboratory's overall ability to carry out a specific test method. If a laboratory's performance is an outlier compared with the group mean, or if it fails to meet a pass/fail criterion, the precise nature of the testing problem cannot be pinpointed. However, unsatisfactory performance clearly indicates that the laboratory is not competent to perform the test method.

In the NVLAP scheme, proficiency testing is viewed as a necessary complement to on-site assessments. Proficiency testing is a means for comparing each participating laboratory to the group performance and assuring that all laboratories do comparable work. It is also a means for maintaining surveillance of the laboratory"s competence at scheduled intervals between assessments. The on-site assessment is a means for determining if laboratory practices, personnel, and physical plant comply with the criteria by which NVLAP defines a quality laboratory. Unlike proficiency testing, the assessment process does not directly address the question of the laboratory"s ability to "get the right answer."

\section{ON-SITE ASSESSMENTS}

On-site assessments of laboratories are performed by technical experts in the fields of testing for which accreditation is sought. These "peer assessors" are not NBS employees: they are consultants, retixed persons, currently employed individuals, academicians, and employees of other government organizations, contracted by NBS for services on an as-needed basis. On-site assessments are the basis for determining the capability of a laboratory to perform specific tests and determining the overali quality of work being done by the laboratory.

NVLAP assessors have both formal and informal objectives in carrying out their on-site tasks. Using checklists, they review and critique laboratory performance in each area specified by the NVLAP criteria. They identify, discuss, and document the laboratory's "deficiencies" relevant to specific criteria. Deficiencies are failures to comply with specific conditions or criteria for accreditation and must be satisfactorily resolved by the laboratory before initial accreditation, or within 30 days of the assessment if the laboratory is already accredited. When opportunities present themselves and if laboratory personnel are receptive, assessors offer suggestions for improving testing quality and the efficiency and effectiveness of laboratory operations, and promote laboratory adoption of the principles of quality assurance inherent in the NVLAP system.

Assessors are vital to NVLAP because their findings play such an important part in the final accreditation decision. In their role as assessors, they do not make formal recommendations to NBS regarding accreditation actions. However, their evaluations of laboratory performance, in terms of the NVLAP criteria, are a major element of the decision to accredit or to deny accreditation. In effect, the assessors are the interpreters of the technical criteria for accreditation and are, therefore, largely responsible for maintaining the quality and reputation of the program. The assessors are indeed representatives of NVLAP and the National Bureau of Standards, and must understand the program and its place within NBS so as not to misrepresent NBS or the implications of NVLAP accreditation. 


\section{DENTIFICATION, EVALUATION, AND SELECTION OF ASSESSORS}

[dentification of potential assessors is accomplished in many ways. The rocess of development of a new accreditation program offers opportunities to inform the technical community of NVLAP's needs for technical experts. NVLAP ublishes announcements of new and expanded programs in trade and technical journals and other media. Public workshops are advertised and held to stablish technical requirements for accreditation. NVLAP staff develop axtensive contacts with technical committees of standards organizations, trade and professional organizations, other government agencies, and are in contact sith NBS technical staff who are aware of other experts in their field. ?otential assessors are identified through many informal interactions and at industry and professional organization meetings. Assessors assigned to stablished programs are asked to recommend colleagues and co-workers who may se qualified.

Potential assessor candidates are contacted by telephone and letter and, if they indicate an interest, are sent an information package describing the program and the role of assessors in it. They are asked to submit a resume lescribing their technical qualifications and experience relevant to NVLAP, and are also asked to identify the test methods (in the applicable field of testing) for which they feel competent to perform assessments and evaluations.

Technical and non-technical criteria are used for evaluating and selecting assessors. Minimum technical qualifications may include the number of years of experience, training, professional degrees, and relevant,certifications. Prospective NVLAP assessors must have extensive technical experience in those fields for which they will evaluate laboratories. In addition, potential assessors should have experience in assessing and evaluating laboratories and direct experience in laboratory management and operations. They should have a sound understanding of laboratory practices for assuring quality testing. The nature and breadth of their activities and participation in technical societies and standards comittees should be such that they are widely recognized as "peers" in their fields.

Two non-technical criteria bear heavily on the selection of assessors. First, they must have no past or current affiliations that would be perceived as a conflict of interest either by NVLAP or the laboratories seeking accreditation. Second, the candidate assessors must be able to interact with laboratory personnel in a firm, constructive, and professional yet nonadversarial manner.

The assessor selection process depends on the particular nature of the NVLAP program in which they will participate and the number of assessors sought. A formal selection process involves establishing a selection panel, comprised of NVLAP staff, other technical experts from NBS, and representatives of public and private organizations in the relevant technical community. The panel develops and assigns weighting factors to selection criteria, reviews each resume, and evaluates and ranks each candidate. This rype of formal process was used effectively to select 14 assessors for the Radiation Dosimetry program.

For a program initially requiring few assessors, the selection process is usually informal. NVLAP staff review resumes and select assessors on the 
basis of technical training and experience and the recommendations of other technical experts in the field.

Final selection of an assessor is conditional on the impressions given and the evaluations made by NVLAP staff throughout the training process. An individual may have outstanding technical credentials and experience, but not the personal qualifications or appropriate temperament for performing onmite assessments.

\section{ASSESSOR TRAINING}

Training of assessors is an on-going, developmental process. Clerical and administrative tasks are fairly straightforward, but the technical aspects of the assessment process are evolutionary as a particular program develops from its early stages to a mature program with an extensive menu of test methods, well-established standards of performance, and proficiency testing programs. The assessor training program can, nonetheless, be divided into three distinct stages: orientation at NBS, the first on-site assessment, and follow-up.

\section{ORIENTATION AT NBS}

After a new program has been established, the selected assessors are invited to attend an orientation and training session conducted at NBS. The sessions generally last two days and the participants are paid for their travel and time. Orientation consists of an overall description of NVLAP goals, objectives, philosophy, and methodology. Training pertains to the description of assessment techniques and procedures and use of NVLAP documents to prepare for, implement, and report on assessments.

The sessions are structured and follow a formal agenda conducted as a seminar by the NVLAP staff. Discussions are interactive and all participants are encouraged to contribute by describing their experiences in visiting and evaluating laboratories and by sharing information on test methods and other technical aspects of the program. Although the primary intent of the orientation is to convey assessment-related information to the technical experts, NVLAP takes advantage of their technical expertise to benefit the program and upgrade the technical criteria for accreditation.

It is important that all assessors have a common understanding of what constitutes a competent laboratory in order that all laboratories receive equivalent evaluations. The orientation session is the first opportunity to accomplish a "calibration" of assessors. This session is also the first step in the process of evaluating the assessors themselves. Note is taken of their preparation for the session, their apparent interest in the proceedings, their apparent understanding of what is expected of them, their communication and listening skills, personality, self-confidence, cooperativeness, professionalism, and general demeanor.

Orientation emphasizes the following areas:

NVLAP Procedures, Policies, and Philosophy --

The NVLAP Procedures prescribe the criteria upon which NVLAP accreditation decisions are based. The Procedures are reviewed in detail to ensure that the assessors thoroughly understand the conditions and implications of NVLAP 
accreditation. The differences between accreditation and product zertification, acceptable references to NVLAP in laboratory advertising, use of the NVLAP logo, ethical business practices expected of the laboratory, and acceptable relationships between a manufacturer's laboratory and its parent company, are discussed. One of $\mathrm{NBS}^{\prime}$ objectives, to be implemented through NVLAP, is the improvement of the quality of testing by laboratories doing commercial work. While the on-site assessment is not meant to be a consulting session for the laboratory, the assessors are encouraged to help and inforra the laboratories, in an appropriate manner, in their areas of expertise.

\section{Criteria for Accreditation --}

The test methods and NVLAP technical documents, including critical elements, checklists, and program Handbook, are reviewed and discussed to promote a common knowledge of the essential aspects of the methods that are focal points during an assessment. The experts are asked to share their experiences in performing and observing the tests and to offer suggestions on key elements of technician performance, equipment, test conditions, and facilities. Review of the test methods allows the participants, rather than NVLAP staff, to lead the discussion and affords the staff an opportunity to observe them in their capacity as technical experts. Discussion of proficiency testing requirements provides insight into the experimental aspect of NVLAP and develops the concept that NVLAP is free to go beyond the limits of the test methods themselves to ascertain laboratory competence.

\section{Assessor Checklists and Reports --}

The assessment report is thoroughly reviewed to assure that the assessors understand the level of detail to which they must evaluate the laboratory and report on their findings. This is their first opportunity to see the report form and the extent of the evaluation required and the seriousness of the task are emphasized. They are shown how the report is keyed to the NVLAP Procedures and general criteria, and NVLAP staff emphasize the need for preparation before the on-site assessment, as well as thoroughness during the assessment, in order to carry out a high quality evaluation.

Assessment Techniques --

Techniques for interviewing laboratory personnel and making observations of laboratory procedures, equipment and procedures, are described from the perspective of many years of NVLAP experience. NVLAP staff recount prior experiences and encounters to describe how to deal with various personal interactions that may occur during an assessment. The experts are encouraged to share their own prior experiences in evaluating testing laboratories. Advice and guidance are given by NVLAP staff on the key elements of the assessment, including:

(1) the first meeting with laboratory management and key personnel, and explanation of the assessment procedures and objectives;

(2) the walk-through of the laboratory and introduction to other laboratory personnel;

(3) discussion of findings with laboratory personnel throughout the assessment;

(4) the exit debriefing, during which the assessor's findings are discussed with laboratory management to ensure that they understand what must be done to achieve or maintain accreditation; and 
(5) avoidance of confrontations or adversarial situations by displaying courtesy, professionalism, and firm commitment to NVLAP objectives.

\section{Role of Technical Experts}

The experts are briefed on their other responsibilities as evaluators and technical experts. In their role as evaluators (not as assessors) they review on-site assessments performed by their colleagues, develop consensus views regarding controversial laboratory assessments and findings, review deficiency corrections, consult with each other on borderline recomendations, and review proficiency test results or other technical information to develop recommendations for accreditation of individual laboratories.

As technical experts, they provide assistance to NVLAP in developing and updating the technical criteria for accreditation in their field of expertise, and advise NVLAP on proposed additions of test methods or proficiency testing requirements to existing programs. In general, they are expected to provide technical advice on any matter relating to requirements for accreditation and implementation of the program.

\section{Constraints on Assessors}

The role of the assessor as NVLAP's representative is emphasized and the constraints on the assessor are discussed in terms of that role. It is important that the assessors, in performing an on-site evaluation, do not put their personal interests ahead of NVLAP concerns. Similarly, they must not indulge in discussions or unwelcome advice that, might lead to internal. conflict, are not in consonance with NVLAP goals and intentions, or reflect badly on NBS. It is emphasized that assessors are bound by the same ethical practices as NBS employees.

An issue that is always raised is the potential for a NVLAP assessor to work as an independent consultant for a laboratory seeking accreditation or already accredited. NVLAP does not object to such contractual arrangements, but they must be dealt with openly and honestly and not compromise the integrity of the program or of the assessor. It is stipulated that assessors do not evaluate the results of their own independent consulting work.

\section{Administrative Details}

Administrative details, including billing and payment procedures are discussed. NVLAP staff provide information on average costs and levels of effort for assessments and other tasks. NVLAP costs for assessments are fully reimbursed through fees collected from the laboratories. Assessors are encouraged to be sensitive to the need to keep fees as low as practical.

At the orientation session, each assessor is provided with an Assessor Manual which contains copies of reference materials, assessment forms, and other documents related to the program(s) for which assessments are to be performed. The manuals are periodically updated and new or revised documents are sent to the assessors to keep them current on all phases of the program.

Prior to a scheduled assessment, the assessor is provided with all appropriate documentation relevant to the assigned laboratory, including copies of the 
application forms submitted by the laboratory, proficiency testing data, and previous assessment reports, if any, as well as any other pertinent information on the laboratory.

\section{INITIAL ON-SITE ASSESSMENT}

The first on-site assessment is a critical phase of the new assessor's training since the abstract discussions at the orientation session become real and have immediate impact. Each new assessor is accompanied by a member of the NVLAP staff on at least the first assessment. The staff person assists the assessor by providing an on-going critique of the proceedings, advising on how to deal with unusual situations, helping to explain NVLAP procedures and policies to laboratory personnel, and generally supplying guidance and emotional support.

Throughout the assessment the NVLAP staff member evaluates the performance of the assessor and, if necessary, privately discusses his:

(1) understanding of NVLAP criteria, procedures, and policy;

(2) knowledge of the test methods and related technology;

(3) effectiveness in the use of the assessment form;

(4) knowledge of the steps in performing the assessment;

(5) ability to identify and discuss deficiencies;

(6) effectiveness of oral and written communication;

(7) handling of any disagreements or arguments;

(8) appropriateness of advice given;

(9) poise in performing the assessment; and

(10) efficient use of time.

If the assessor does not demonstrate confidence in carrying out an assessment, he will be accompanied by a NVLAP staff member or an experienced assessor on a second assessment for further evaluation. If an assessor is found to be unacceptable for reasons of personality, temperament, ability to communicate, or other reason, he will not be asked to perform further assessments.

FOLLOW UP

After a program has been operating for approximately 2 years, the assessors are reconvened to share their experiences. The sessions are conducted by a NVLAP staff person and are generally informal interactive sessions. This provides an opportunity for exchanging ideas on assessment techniques, problem areas encountered and problem-solving, on refinements to the evaluation criteria and for improving the evaluation process. These sessions are held either at NBS or are scheduled in conjunction with a professional society meeting which the assessors are likely to attend.

Occasionally a program is substantially modified by adding test methods or changing test methods already included in the program. When such changes occur, a session is held to update the assessors as to the changes required in the assessments. 
The continuing acceptability of assessors is conditional on their performance of assessments and evaluations in an objective, professional manner and in accordance with NVLAP policies. Assessor performance is reviewed at least annually, and more frequently if questions arise as to their ability to carry out assigned duties or before a particularly sensitive or critical assessment is assigned.

\section{FUTURE ACTIVITIES IN ASSESSOR TRAINING}

The requirement that NVLAP be self-supporting and the determination to keep laboratory fees as low as practicable preclude the maintenance of sufficient staff, or use of more than one assessor, to implement a team approach to onsite assessments. Our reliance on a single, unaccompanied assessor to evaluate a laboratory demands that assessor training receive a very high priority. Frequent informal discussions and interactions form the basis for on-going training, but there is a need to increase the scope of formal training. Within the limits of time and funding, plans are in progress to develop training films, begin limited use of a "buddy" system for particularly difficult or controversial assessments, and to use formal debriefing and feedback following assessments. In addition, a NVLAP Operations Manual provides detailed information on how NVLAP operates and describes standards of performance to assure a high quality program. The Manual will be one of several training devices for assessors to give them more detailed information on NVLAP functions and operations relevant to the planning and implementation of on-site assessments. NVLAP will continue to review assessor training programs used by other national systems to learn of new approaches to training that can be adopted by the NVLAP system. 
1. TITLE AND SUBTITLE

NVLAP Assessor Selection and Training

\section{AUTHOR(S)}

Harvey W. Berger

i. PERFORMING ORGANIZATION (If joint of other than NBS, see instructions)

7. Contraev/Grant No.

\section{NATIONAL BUREAU OF STANDARDS \\ U.S. DEPARTMENT OF COMMERCE \\ GAITHERSBURG, MD 20899}

9. SPONSORING ORGANIZATION NAME AND COMPLETE ADDRESS (Street. Gity, Stote, ZIP)

Same as 6.

10. SUPPLEMENTARY NOTES

Document describes a computer program: SF-185, FIPS Software Summary, is attached.

1. ABSTRACT (A 200-word or less factual summary of most significant information. If document includes a significant bibliography or literoture survey. mention it here)

The role and importance of "peer" assessors in the National Voluntary Laboratory Accreditation Program (NVLAP) is discussed. Procedures for identification, evaluation, and selection of assessors are described and the elements of assessor orientation and training are presented.

12. KEY WORDS (Six to iwelve entries: alphabetical order; capitalize only proper names: and separate key words by semicolons) accreditation; assessment; assessor; laboratory accreditation; proficiency testing; NVLAP

13. AVAILABILITY

$\triangle X$ Unlimited

$\square$ For Official Distribution. Do Not Release to NTIS

$\square$ Order From Suderintendent of Documents, U.S. Government Printing Office, Washington, D.C. 20402.

Order From National Technical Information Service (NTIS), Springfield。VA. 2216I
14. NO. OF

PRINTED PAGES

11

15. Price

$\$ 9.95$ 
$-$ 